\title{
Erectile Dysfunction in Chronic Hemodialysis Patients at the University Hospital Center of Point-G in Mali
}

\author{
Seydou Sy ${ }^{1,2 *}$, Magara Samaké ${ }^{2,3}$, Hamadoun Yattara1,2, Moctar Coulibaly4, Ibrahima Koné5, \\ Aboubacar Sidiki Fofana1, Djénèba Diallo1,2, Atabieme Kodio1, Modi Sidibé1, \\ Nouhoum Coulibaly¹, Alkaya Touré1, Djibril Sy ${ }^{2,6}$, Moustapha Tangara ${ }^{1,2}$, Saharé Fongoro ${ }^{1,2}$
}

\author{
${ }^{1}$ Nephrology and Haemodialysis Department of the CHU of Point G, Bamako, Mali \\ ${ }^{2}$ Faculty of Medicine, University of Bamako, Bamako, Mali \\ ${ }^{3}$ Nephrology Unit of the Fousseyni DAOU Hospital of Kayes, Kayes, Mali \\ ${ }^{4}$ Nephrology Unit of Mali GAVARDO Hospital, Bamako, Mali \\ ${ }^{5}$ Nephrology Unit of the Regional Hospital of Mopti, Mopti, Mali \\ ${ }^{6}$ Internal Medicine Service at the University Hospital Center of Point G, Bamako, Mali \\ Email: *seydousy2002@yahoo.fr
}

How to cite this paper: Sy, S., Samaké, M., Yattara, H., Coulibaly, M., Koné, I., Fofana, A.S., Diallo, D., Kodio, A., Sidibé, M., Coulibaly, N., Touré, A., Sy, D., Tangara, M. and Fongoro, S. (2020) Erectile Dysfunction in Chronic Hemodialysis Patients at the University Hospital Center of Point-G in Mali. Open Journal of Clinical Diagnostics, 10, 29-40.

https://doi.org/10.4236/ojcd.2020.101003

Received: December 24, 2019

Accepted: February 11, 2020

Published: February 14, 2020

Copyright $\odot 2020$ by author(s) and Scientific Research Publishing Inc. This work is licensed under the Creative Commons Attribution International License (CC BY 4.0).

http://creativecommons.org/licenses/by/4.0/ (c) (i) Open Access

\begin{abstract}
Introduction: Erectile Dysfunction (ED) is defined as the inability to achieve or maintain an erection sufficient for sexual intercourse. The frequency of erectile dysfunction in patients with kidney failure is estimated at $50 \%$ to $70 \%$. The objective of this work was to determine the frequency of sexual dysfunction in chronic hemodialysis patients, to evaluate the psycho-social impact and to describe hormonal disturbances. Patients and Methods: This was a descriptive prospective study carried out from 3 April to 31 August 2017 in the nephrology and haemodialysis department of the Point G University Hospital. She has been interested in men over the age of 18 who have been on chronic hemodialysis for more than a year. Sexual dysfunction was assessed using the questionnaire: International Index of Erectile Function (IIEF-5). Results: Sixty-five patients were included. Forty-six $(70.8 \%)$ had severe (30.8\%), moderate (13.8\%) and mild (26.2\%) ED. 56.9\% of patients had libido disorders, with decreased sexual desire (38.5\%); absent sexual desire $(18.5 \%)$. Sexual desire was normal in $43.1 \%$ of patients. Sexual activity was absent in 20 patients (30.8\%). Sexual rigidity was reduced in 28 patients (43.1\%) and normal in 24 patients (36.9\%). The mean age of our patients was 42.55 years with a median age of 40 years and extremes of 23 and 74 years. Eighty percent were married. Nine patients $(13.8 \%)$ were using sildenafilbased medications. Antihypertensives were prescribed in $93.9 \%$ and erythropoietin in $30.8 \%$ of patients. The main impact groups were anxiety (53.8\%),
\end{abstract}


fear of failure (27.7\%), insomnia (7.7\%) and anxiety (6.1\%). And defence mechanisms included: understanding (54.7\%); isolation (24.6\%); repression (7.7\%); quarrel (7.7\%); and divorce in 1 case $(1.5 \%)$. The occurrence of ED was related to hypotestosterolemia $(\mathrm{p}=0.030)$, and between low libido and testosterone $(p=0.001)$. Nutritional status was satisfactory in $78.4 \%$ of our patients. Moderate and at and severe undernutrition was found in equal proportions $(10.8 \%)$ in our patients with a statistically significant relationship with the occurrence of erectile dysfunction $(p=0.015)$. There was no correlation between ED and duration of dialysis $(p=0.715)$, the existence of inflammatory syndrome $(\mathrm{p}=0.870)$, age $(\mathrm{p}=0.249)$ and diabetes, hypertension, smoking $(\mathrm{p}=0.442)$. Sexual activity was decreased in 41 patients with $\mathrm{Hb}<10 \mathrm{~g} / \mathrm{dl}(\mathrm{p}=0.340)$. Conclusion: Sexual disorders are common in hemodialysis patients. Psychological support of the patient is essential throughout the therapeutic sequence of erectile dysfunction, whatever the molecule or physical means considered.

\section{Keywords}

Erectile Dysfunction, Renal Failure, Dialysis, Mali

\section{Introduction}

Erectile dysfunction (ED) is defined as the inability to achieve or maintain an erection sufficient for sexual intercourse [1].

Erectile dysfunction is a common condition in the general population. The frequency of these erectile dysfunctions is increased in certain special populations such as patients with renal insufficiency, where it is estimated at $50 \%$ to $70 \%$ depending on the stage of renal failure [2]. In this population even more than in the general population, ED appears to be of multiple etiologies, combining organic and psychological disorders [2].

While kidney transplantation is the treatment of choice for end-stage renal disease, it appears to have widely varying effects on ED. Indeed, it can improve the ED as well as the overall quality of life.

The incidence of ED in this specific population is not easy to assess as it is still a taboo subject. However, some epidemiological studies show that it may affect more than $50 \%$ of dialysis or transplant patients, with the extent of ED directly correlated with disease severity [3].

In Benin the frequency of erectile dysfunction was $75.9 \%$, of which $29.3 \%$ were severe erectile dysfunction [4].

In 2013, a study conducted in Senegal found that $57 \%$ of the patients included had mild to moderate ED [5].

At first glance, sexual problems are often considered secondary in these patients. However, taking them into account in the overall management of these patients contributes greatly to improving their quality of life. In the last ten years, significant progress has been made in the management of ED in patients 
with chronic renal failure and transplantation, particularly since the development of phosphodiesterase type 5 inhibitors [3].

The objective of this work was to determine the frequency of sexual dysfunction in chronic hemodialysis patients, to evaluate the psycho-social impact and to describe hormonal disturbances.

\section{Patients and Methods}

This was a descriptive prospective study carried out from April 3 to August 31, 2017 in the nephrology and hemodialysis department of the CHU du Point G. She has been interested in male patients over the age of 18 who have been on chronic hemodialysis for more than a year. Not included were hemodialysis patients with:

- Acute renal failure

- Uncontrolled diabetes,

- Uncontrolled heart disease

- Refusal to participate in the study,

- Acute complication during hospitalization.

Sexual dysfunction was assessed using the International Index of Erectile Function (IIEF-5) questionnaires. It consists of five main sections, each with five questions rated from 1 to 5 that explore the quality of sexual intercourse, sexual desire and overall satisfaction with sexual intercourse. For interpretation, a score has been established; thus, erectile dysfunction is defined as severe (score 5 - 10), moderate (11 - 15), mild (score 16 - 20), absent (score 21 - 25). Erectile strength was defined as: normal rigidity, reduced rigidity but allowing penetrative sex, reduced rigidity not allowing penetrative sex, and no erection. All patients were given a full clinical examination. The data are collected on a pre-established anonymous survey form. The parameters studied were:

- socio-demographic: age, marital status, occupation,

- co-morbidities: diabetes, hypertension, smoking,

- etiological factors,

- number of years spent on haemodialysis,

- type of causal kidney disease.

- Sexual activity: absence of sexual activity, at least once/week, at least once/15 days, at least once/month and less than once/month.

- residual diuresis: 24-hour urine volume greater than or equal to $500 \mathrm{ml}$.

- Biological: testosterone, haemoglobin level, blood sugar, blood calcium, phosphorus, parathormone, albumin, CRP.

- The psycho-social impact:

${ }^{\star}$ Large groups of psychic repercussions: anxiety, anguish, fear of failure, insomnia.

${ }^{\star}$ Mechanical defense reactions: understanding, repression, isolation, argument, divorce.

- Treatment in progress: antihypertensive, erythropoiesis-stimulating agents 
and other drugs. All participating patients signed free and informed consent after a broad explanation of the purpose of the study.

Data entry was performed with Word 2010 software, with statistical analysis performed by SPSS version 18 software. The Statistical Comparison Test was Chi-square with a value of $\mathrm{p}<0.05$ considered statistically significant.

\section{Results}

Sixty-five patients met the inclusion criteria. Forty-six patients or $70.8 \%$ had erectile dysfunction (ED); defined as severe (30.8\%), moderate (13.8\%) and mild (26.2\%). Libido disorders were present in $56.9 \%$ of patients, with decreased sexual desire (38.5\%); absent sexual desire (18.5\%). Sexual desire was normal in $43.1 \%$ of patients. Sexual activity was absent in 20 patients (30.8\%). Sexual rigidity was reduced in 28 patients (43.1\%) and normal in 24 patients (36.9\%). The mean age of our patients was 42.55 years with a median age of 40 years and extremes of 23 and 74 years. Fifty-two point three percent (52.3\%) were between the ages of 18 and 40 . ED was common (70.58\%) in patients 18 to 40 years of age but not significant ( $\mathrm{p}=0.241)$ (c.f Table 1$)$.

Civil servants and traders accounted for 30.8 and 30.8 per cent respectively. Bride and groom accounted for $80 \%$ of patients. The co-morbidities were: hypertension (56.9\%), diabetes (9.3\%), tobacco (6.2\%). Initial nephropathy was vascular in $50.8 \%$ of cases. Patients with less than 3 years of dialysis were the most affected by a lack of sexual activity at $13.84 \%$, which was statistically insignificant $(\mathrm{p}=0.715)$. The average length of time on dialysis was 4.38 years. Residual diuresis was found in $12.3 \%$ of cases. Patients with diuresis had no erectile dysfunction in $75 \%(6 / 8)$ of cases ( $\mathrm{p}=0.024)$ (c.f Table 2).

A hemoglobin level $<10 \mathrm{~g} / \mathrm{dL}$ was found in $78.5 \%$ of cases. The average $\mathrm{Hb}$ level was $8.56 \mathrm{~g} / \mathrm{dL}$. HPR was increased in $40 \%$ of cases. Testosterone levels were normal in $83.1 \%$ of cases, low in $12.3 \%$ and high in $4.6 \%$ of cases. Albumin levels above $38 \mathrm{~g} / \mathrm{l}$ were found in $78.6 \%$ of cases and below $35 \mathrm{~g} / \mathrm{l}$ in $10.8 \%$. A normal parathormone was observed in $64.8 \%$ of cases and elevated (above $585 \mathrm{ng} / \mathrm{ml}$ ) in 13 patients or $24.1 \%$. The phospho-calcium product was normal (Normal $<4.4$ $\mathrm{mmol}^{2} / \mathrm{L}$ ) in $76.9 \%$ of cases. The main impact groups were anxiety $(53.8 \%)$, fear of failure (27.7\%), insomnia (7.7\%) and anxiety (6.1\%). And defence mechanisms

Table 1. Distribution of patients by age and erectile dysfunction.

\begin{tabular}{|c|c|c|c|c|c|}
\hline \multirow{2}{*}{ Age } & \multicolumn{4}{|c|}{ Dysfunction erectile } & \multirow{2}{*}{ Total } \\
\hline & severe $\mathrm{TE}$ & moderate ET & Light TE & normal OT & \\
\hline $18-40$ & 9 & 4 & 11 & 10 & $34(52.3 \%)$ \\
\hline $41-60$ & 6 & 4 & 6 & 9 & $25(38.5 \%)$ \\
\hline Above 60 & 5 & 1 & 0 & 0 & $6(9.2 \%)$ \\
\hline Total & $20(30.8 \%)$ & $9(13.8 \%)$ & $17(26.2 \%)$ & $19(29.2 \%)$ & $65(100 \%)$ \\
\hline
\end{tabular}

TE: erectile dysfunction; Erectile dysfunction was common in patients aged 18 to 40 years, $70.58 \%(24 / 34)$ of cases with $\mathrm{p}=0.241$. (Chi $2=18.41$; dd: 15$)$. 
included: understanding (54.7\%); isolation (24.6\%); repression (7.7\%); quarrel (7.7\%); and divorce in 1 case (1.5\%).

The occurrence of ED was related to hypotestosteroemia $(\mathrm{p}=0.030)$, and between low libido and testosterone $(\mathrm{p}=0.001)$ (c.f Table 3 and Table 4). Nutritional status was satisfactory in $78.4 \%$ of our patients. Moderate and in and severe undernutrition was found in equal proportions $(10.8 \%)$ in our patients with a statistically significant relationship with the occurrence of erectile dysfunction $(p=0.015)$ (c.f Table 5). There was no correlation between ED and duration of dialysis $(\mathrm{p}=0.715)$, the existence of inflammatory syndrome $(\mathrm{p}=0.870)$, age $(\mathrm{p}$ $=0.249)$ and diabetes, hypertension, smoking $(\mathrm{p}=0.442)$. Sexual activity was

Table 2. Distribution of patients by diuresis and erectile dysfunction.

\begin{tabular}{cccc}
\hline \multirow{2}{*}{ Dysfunction erectile } & \multicolumn{2}{c}{ Diuresis } & Total \\
\cline { 2 - 3 } & No & Yes & \\
\hline Severe & 19 & 1 & $20(30.8 \%)$ \\
Moderate & 9 & 0 & $9(13.8 \%)$ \\
Light & 16 & 1 & $17(26.2 \%)$ \\
Normal & 13 & 6 & $19(29.2 \%)$ \\
Total & $57(87.7 \%)$ & $8(12.3 \%)$ & $65(100 \%)$ \\
\hline
\end{tabular}

Patients with diuresis had no erectile dysfunction in $75 \%(6 / 8)$ of cases with $\mathrm{p}=0.024$. (Chi 2: 9.44; ddl: 3).

Table 3. Distribution of patients according to testosteronemia and erectile dysfunction.

\begin{tabular}{ccccc}
\hline \multirow{2}{*}{ Dysfunction erectile } & \multicolumn{3}{c}{ Testosterone } & \multirow{2}{*}{ Total } \\
\cline { 2 - 4 } & Bass & Normal & High & \\
\hline Severe & 6 & 13 & 1 & $20(30.8 \%)$ \\
Moderate & 2 & 6 & 1 & $9(13.8 \%)$ \\
Light & 0 & 16 & 1 & $17(26.2 \%)$ \\
Normal & 0 & 19 & 0 & $19(29.2)$ \\
Total & $8(12.3 \%)$ & $54(83.1 \%)$ & $3(4.6 \%)$ & $65(100 \%)$ \\
\hline
\end{tabular}

Erectile dysfunction was associated with hypotestosteronemia in 8 patients or $12.30 \%$ of cases with $\mathrm{p}=$ 0.030. (Chi 2: 13.98; ddl: 6).

Table 4. Distribution of patients according to testosteronemia and libido disorders.

\begin{tabular}{ccccc}
\hline Libido & \multicolumn{3}{c}{ Testosteronemia } & \multirow{2}{*}{ Total } \\
\cline { 2 - 4 } & Bass & Normal & High & \\
\hline Normal & 0 & 28 & 0 & $28(43 \%)$ \\
diminished & 3 & 19 & 3 & $25(38.5 \%)$ \\
Absent & 5 & 7 & 0 & $12(18.5 \%)$ \\
Total & $8(12.3 \%)$ & $54(83.1 \%)$ & $3(4.6 \%)$ & $65(100 \%)$ \\
\hline
\end{tabular}

There was a libido disorder in all patients with low testosteronemia, $12.30 \%$ of cases with $\mathrm{p}=0.001$. (khi 2 : 18.65, ddl: 4). 
Table 5. Distribution of patients by nutritional status and erectile dysfunction.

\begin{tabular}{ccccc}
\hline \multirow{2}{*}{ Dysfunction erectile } & \multicolumn{3}{c}{ Albuminemia } & Total \\
\cline { 2 - 4 } & Sup at 38 & $\mathbf{3 5 - 3 7 . 5}$ & inf to 35 & \\
\hline Severe & 10 & 4 & 6 & $20(30.8 \%)$ \\
Moderate & 8 & 1 & 0 & $9(13.8 \%)$ \\
Light & 15 & 1 & 1 & $17(26.2 \%)$ \\
Normal & 18 & 1 & 0 & $19(29.2 \%)$ \\
Total & $51(78.4 \%)$ & $7(10.8 \%)$ & $7(10.8 \%)$ & $65(100 \%)$ \\
\hline
\end{tabular}

Erectile dysfunction was associated with severe undernutrition in 7 patients or $10.8 \%$ of cases with $\mathrm{p}=$ 0.015. (Chi 2: 15.79, ddl: 6).

decreased in 41 patients with $\mathrm{Hb}<10 \mathrm{~g} / \mathrm{dl}$ but not statistically significant $(\mathrm{p}=$ 0.340). Antihypertensive therapy was prescribed in $93.9 \%$ of patients. Epo was prescribed in $30.8 \%$ of patients. Nine patients or $13.8 \%$ were using medication containing sildenafil and $86.2 \%$ were abstaining.

\section{Discussion}

The high cost of additional tests, non-consent and the low level of patient education limited our study.

It has been shown that sexual dysfunction is frequently encountered in patients with CKD in the hemodialysis stage [6] [7]. These patients are exposed to a certain number of co-morbidities (hypertension, diabetes, depression, etc.) which increase the frequency of these disorders compared to the general population.

In our study, the prevalence of ED was $70.8 \%$. It was moderate (13.8\%), severe (30.8\%), mild (26.2\%). In the study by Avakoudjou et al. [4], ED was present in $75.9 \%$ of hemodialysis patients and was severe in $29.3 \%$, moderate and mild in $20.7 \%$ and $25.8 \%$, respectively. Kharbach et al. found a frequency of ED in $78 \%$ of patients, with mild in $23 \%$, mild to moderate in $30 \%$, moderate in $18 \%$, and severe in $6 \%$ of cases [8].

The average age of our patients was 42.55 years with a median age of 40 years and extremes of 23 and 74 years. Kharbach et al. had returned to an average age of 45.5 years and extremes of 18 and 75 years [8]. On the other hand, the population appears older in the Leonardo EM study [9] which reported a mean age of 50.2 years \pm 14 years. The most represented age group was between 18 and 40 years old, or $52.3 \%$ in our study. In the literature [10] [11], the prevalence of erectile dysfunction increased with patient age ranging from $69 \%$ for patients aged 20 - 50 years to $78 \%$ for patients over 50 years. There was no statistically significant relationship between age and the occurrence of erectile dysfunction in our series $(p=0.241)$. Civil servants and shopkeepers were the most identified socio-professional groups with $30.8 \%$ for each, which can be explained by the high financial cost of chronic dialysis.

Married people accounted for $80 \%$ and single people for $20 \%$ of patients, which may be explained by the fact that men marry early for religious and cul- 
tural reasons.

The most common co-morbidities were hypertension in $56.9 \%$ and diabetes in 9.3\% of patients. In contrast, Avakoudjo in Benin [4] recovered from hypertension $(87.9 \%)$ and diabetes $(12.1 \%)$. There was no significant association between diabetes, hypertension, smoking and the occurrence of sexual dysfunction in our patients $(\mathrm{p}=0.442)$.

Vascular pathologies are risk factors for the elderly, especially because of the associated endothelial dysfunction. The latter would be largely responsible for the ED. Vascular nephropathy was the most common etiology at $50.8 \%$ of cases, followed by chronic glomerulonephritis (24.6\%) and in $13.8 \%$ of cases no underlying etiology was found. There was no statistically significant correlation between ED and initial nephropathy ( $p=0.419)$.

The average age on hemodialysis was 4.38 years for extremes of 12 months and 16 years. In our series there was no relationship between the length of time on dialysis and the occurrence of the disorder. This is in line with several studies [11] [12]. Diuresis was maintained in 8 patients or $12.30 \%$ of cases. We found the absence of erectile dysfunction in $75 \%$ of cases in these patients compared to oligoanuric patients, so the absence of diuresis was significantly related to the occurrence of sexual dysfunction with $\mathrm{p}<0.024$. Anemia was found in the majority of our patients, with hemoglobin levels $<10 \mathrm{~g} / \mathrm{dl}$ in $78.46 \%$ of cases and a mean of $8.56 \mathrm{~g} / \mathrm{dl}$ with extremes of 5 and $15.1 \mathrm{~g} / \mathrm{dl}$. This is a factor usually seen in patients with chronic renal failure but was not related to the occurrence of sexual dysfunction ( $p=0.249)$. Malekmakam [11] and Naya [12] found no significant relationship between anaemia and ED. In our series, nutritional status was satisfactory in $78.4 \%$ of our patients. Moderate and at and severe undernutrition was found in equal proportions $(10.8 \%)$ in our patients with a statistically significant relationship with the occurrence of erectile dysfunction $(p=0.015)$. Endocrine and metabolic disturbances are numerous and affect the quality of erection. [13]. Hyperparathyroidism was noted in $24.1 \%$ of cases with a PTH level greater than 9 times the upper norm, but no correlation between sexual disorders and hyperparathyroidism was found $(\mathrm{p}=0.286)$. Numerous studies have reported a decrease in testosterolemia in hemodialysis patients with erectile dysfunction, libido and orgasm [14] [15]. In our study, testosteronemia was normal in $83.1 \%$ of cases and significantly lower in patients with sexual dysfunction with $(\mathrm{p}=0.030)$. Impaired libido was observed in $57 \%$ of our patients and significantly related to decreased testosterone levels $(\mathrm{p}=0.001)$. Penile rigidity was reduced but allowed sexual intercourse in 25 patients or $38.5 \%$ and was normal in 24 patients or $36.9 \%$.

We found that $69.2 \%$ of our patients were sexually active as follows: 12 patients had sex at least once a week (18.5\%), 14 patients had sex at least once every 15 days (21.5\%), 16 patients had sex at least once a month (24.6\%) and 3 patients had less than once a month (4.6\%). The use of sexual stimulants based on Sildenafil after medical consultation or self-medication on the advice of friends was observed in 9 patients, i.e. $13.8 \%$. Two patients had noted a slight 
improvement after this treatment, i.e. $22.2 \%$. In other studies of ED in hemodialysis patients, care utilization ranged from 1 to 9.6\% [16] [17]. Even if ED is becoming a real topic of discussion, it remains a taboo subject for many men and sometimes even for the medical profession [18]. The main groups of effects were psychic: Anxiety (53.8\%); fear of failure (27.7\%); Insomnia (7.7\%) and anxiety (6.1\%). On the other hand, in Dakar CISSE [5] had regained anxiety (24\%); fear of failure (22.5\%); anxiety (1.5\%); insomnia (16\%). Depression, anxiety and depression syndrome, and loss of self-esteem are all complementary factors, frequent in these patients, that play a role in the genesis of ED [19]. Mechanical defence reactions were marked by understanding in (54.7\%); isolation (24.6\%); repression (7.7\%); quarrel (7.7\%); divorce (1.5\%). In our series, taking antihypertensive medication was not associated with any sexual dysfunction. Antihypertensive therapy was prescribed in $93.9 \%$ of patients and EPO-stimulating agents in $35.4 \%$.

\section{Conclusion}

Sexual disorders are common in hemodialysis patients. Psychological support of the patient is essential throughout the therapeutic sequence of erectile dysfunction, whatever the molecule or physical means considered.

\section{Conflicts of Interest}

The authors declare no conflicts of interest regarding the publication of this paper.

\section{References}

[1] Carson, C.C., Kirby, R.S. and Goldstein, I. (1999) Textbook of Erectile Dysfunction. Isis Medical Media, Oxford, 917-922.

[2] Kleinclauss, F., Kleinclauss, C. and Bittard, H. (2005) Erectile Dysfunction in Patients with Renal Insufficiency and Renal Transplantation. Advances in Urology, 15, 447-456.

[3] Phé, V., Roupret, M., Ferhi, K., Barrou, B., Cussenot, O. and Traxer, O. (2009) Etiology and Management of Erectile Dysfunction in Chronic Renal Failure. Advances in Urology, 19, 1-7. https://doi.org/10.1016/j.purol.2008.07.003

[4] Avakoudjo, J., Paré, A., Vigan, J., Gandaho, I., Hounasso, P. and Hodonou, R. (2012) Erectile Dysfunction in Haemodialysis Patients at the CNHU-HKM in Cotonou: Epidemiological Profile. Andrologie, 22, 246-251. https://doi.org/10.1007/s12610-012-0201-4

[5] Cisse, M., et al. (2014) Erectile Dysfunction in Chronic Dialysis Patients in Dakar. Néphrologie \& Thérapeutique, 10, 329. https://doi.org/10.1016/j.nephro.2014.07.102

[6] Levy, N.B. (1973) Sexual Adjustment to Maintenance Hemodialysis and Renal Transplantation; National Survey by Questionnaire; Preliminary Report. Transactions-American Society for Artificial Internal Organs, 19, 138-143. https://doi.org/10.1097/00002480-197301900-00025

[7] Peces, R., Horcajada, C. and Lopez-Novoa, J.M. (1981) Hyperprolactinemia in Chronic Renal Failure: Impaired Responsiveness to Stimulation and Suppression. 
Nephron, 28, 11-16. https://doi.org/10.1159/000182087

[8] Kharbach, Y., Bourouhou, H., Tenkorang, S., Mellasa, S., El Ammari, J.E. and Tazi, M.F. (2016) Correlations between Sexual Dysfunction and the Clinico-Biological Profile of Renal Failure in Hemodialysis. African Journal of Urology, 22, 310-314.

[9] Leonardo, E.M., Joaquim, A.C., Archimedes, N., Enrico, A., Valdemar, O. and Miguel, S. (2007) Erectile Dysfunction in Patients with Chronic Renal Failure. International Brazilian Journal of Urology, 33, 673-678. https://doi.org/10.1590/S1677-55382007000500008

[10] Strippoli, G.F.M. (2012) Sexual Dysfunction in Women with ESRD Requiring Hemodialysis. Clinical Journal of the American Society of Nephrology, 7, 974-981. https://doi.org/10.2215/CJN.12601211

[11] Malekmakan, L., Shakeri, S., Haghpanah, S., Pakfetrat, M., Sadeghi, S. and Malekmakan, A. (2011) Epidemiology of Erectile Dysfunction in Hemodialysis Patients Using IIEF Questionnaire. Saudi Journal of Kidney Diseases and Transplantation, 22, 232-236.

[12] Naya, Y., Soh, J., Ochiai, A., Ochiai, A., Mizutani, Y., Ushijima, S., et al. (2002) Significant Decrease of the International Index of Erectile Function in Male Renal Failure Patients Treated with Hemodialysis. International Journal of Impotence Research, 14, 172-177. https://doi.org/10.1038/sj.ijir.3900854

[13] Ahmed, E.A. (2012) Erectile Dysfunction in Hemodialysis: A Systematic Review. World Journal of Nephrology, 1, 160-165. https://doi.org/10.5527/wjn.v1.i6.160

[14] Sawin, C.T., Longope, G., Schmitt, G.W. and Ryan, R.S. (1973) Blood Levels of Gonadotrophins and Gonadal Hormones in Gynecomastia Associated with Chronic Hemodialysis. The Journal of Clinical Endocrinology \& Metabolism, 36, 988-990. https://doi.org/10.1210/jcem-36-5-988

[15] Tourkantonis, A., Spiliopoulos, A., Pharmakiotis, A. and Settas, L. (1981) Haemodialysis and Hypothalamo-Pituitry-Testicular Axis. Nephron, 27, 271-272. https://doi.org/10.1159/000182066

[16] Messina, L., Claro, J. and Nardozza, A. (2007) Erectile Dysfunction in Patients with Chronic Renal Failure. International Brazilian Journal of Urology, 33, 673-678. https://doi.org/10.1590/S1677-55382007000500008

[17] Lobna, A., Rim, M., Asma, B.H., Fadwa, C., Faiçal, J., Jamil, H., et al. (2015) Sexual Disorders in the Hemodialysis Patient. La Tunisie Médicale, 93, 79-84.

[18] Buvat, J., Ratajczyk, J. and Lemaire, A. (2002) Erection Problems: A Suffering That Is Still Too Often Hidden. Andrology, 12, 73-83. https://doi.org/10.1007/BF03034950

[19] Zbiti, N., Benrais, N., Ould Mohamed, A., Hamzaoui, H., Rhou, H., Ouzeddoun, N., et al. (2010) Gonadal Disorders in Male Chronic Hemodialysis. J Maroc Urol, 22. 


\section{Hemodialysis Patient Tracking Sheet}

Questionnaire No.

\section{Q1. Identification:}

Name:

First names:

Age: (year)

Age range / / $1=20-30 ; \quad 2=31-40 ;$

$3=41-50 ; \quad 4=51-60 ;$

$5=61-70 ;$

$6 \geq 70$;

Occupation / / 1 = civil servant;

2 = shopkeeper;

3 = student/student;

4 = worker;

5 = retired;

$6=$ others

Residence: / / 1= Bamako,

$2=$ Outside Bamako, $\quad 3=$ Sub-region

Married: / / Single: / /

\section{Q2. Etiological factors:}

Alcohol: $1=$ Yes $2=$ No, $\quad$ Tobacco: $1=$ Yes $\quad 2=$ No

\section{Q3. Type of causal nephropathy:}

$$
1=\mathrm{CNG} ; \quad 2=\text { Diabetic } \quad 3=\text { Vascular } \quad 4=\mathrm{NIC} ; \quad 5=\mathrm{PKR} ; \quad 6=\text { Other }
$$

Q4. Duration in hemodialysis: / / years

$$
1 \leq 5 \text { years; } \quad 2=5-10 \text { years; } \quad 3=10 \text { years }-15 \text { years; } \quad 4 \geq 15 \text { years }
$$

Q5. Residual diuresis: $\mathrm{CC} / 24 \mathrm{~h}$

Q6 Erectile dysfunction:

$$
1=\text { Before dialysis; } 2 \leq 5 \text { years on dialysis; } \quad 3 \geq 5 \text { years on dialysis; } \quad 4=\text { Other }
$$

\section{Q7. Further examinations}

\section{BIOLOGY}

- Hopper value /

Calcium balance Value / /; calcium /

\begin{tabular}{|c|c|c|c|}
\hline VitD3 Value /___ /; & $1=$ Low & 2 = Normal; & $3=$ High \\
\hline \multirow[t]{2}{*}{ PTH: Value /___ /; } & 1 = Low & 2 = Normal; & 3 = Very High > X 9 normal value; \\
\hline & \multicolumn{3}{|c|}{$4=$ High $<$ X 9 normal value } \\
\hline \multicolumn{4}{|l|}{ - CBC count: } \\
\hline Hemoglobin level /__ / & $1=3-6$ & $2=6-9$ & $3=9-12$ \\
\hline \multirow[t]{2}{*}{ Anemia /__ /; } & $1=$ normo $-\mathrm{c}$ & am normocytic; & $2=$ microcytic hypochromatic \\
\hline & $3=$ normocy & ochromatic & \\
\hline CRP: & $1=$ Normal; & $2=$ High & \\
\hline Testosteronimy:/ & $1=$ Normal; & 2 = High; & $3=\mathrm{Low}$ \\
\hline Albuminemia: & 1 = Normal; & $2=$ Low & \\
\hline
\end{tabular}

$$
1 \text { = hypocalcemia; } 2 \text { = hypercalcemia; } \quad 3 \text { = normal calcium; } \quad 4 \text { = Hyperphosphatemia; }
$$

Phosphoremia 1 = hypo phosphoremia /__ / 2 = normal phosphoremia /__/; $3=$ Hyperphosphatemia $/$ 
Questionnaire IIEF-5: Assessment of sexual potency

Q8. How sure were you that you could get an erection and maintain it?
1. Not sure at all.
2. Not very sure.
3. Moderately safe
4. Sure
5. Very safe

Q9. When you have had erections as a result of sexual stimulation, how often has your penis been stiff enough (hard) to allow penetration?

0 . I have not been sexually stimulated

1. Almost never or never

2. Rarely (much less than half the time)

3. Sometimes (about half the time)

4. Most of the time (much more than half the time)

5. Almost all the time or all the time

Q10. When you tried to have sex, how often were you able to stay erect after penetrating your partner?

0 . I didn't try to have sex.

1. Almost never or never

2. Rarely (much less than half the time)

3. Sometimes (about half the time)

4. Most of the time (much more than half the time)

5. Almost all the time or all the time

Q11. During sex, how difficult was it for you to keep an erection until you had sex?

0 . I didn't try to have sex.

1. Extremely difficult

2. Very difficult

3. Difficult

4. A little difficult.

5. Not difficult.

Q12. When you tried to have sex, how often were you satisfied?

0 . I didn't try to have sex.

1. Almost never or never

2. Rarely (much less than half the time)

3. Sometimes (about half the time)

4. Most of the time (much more than half the time)

5. Almost all the time or all the time

Q13. Do you want to have sex? O yes O no

Q14. Do you have sexual intercourse? O yes $O$ no

Q15. Do you have erections? O Yes, with normal rigidity.

$\mathrm{O}$ Yes, with reduced rigidity, but allowing penetrative sex. 
$\mathrm{O}$ Yes, with reduced rigidity, not allowing penetrative sex

O No, no erection.

Q16. Do you take medication to promote erections? O yes $\mathrm{O}$ no

Q17. If yes, which one(s)?

O Viagra O Cialis O Levitra O Edex O Caverject O other

Q18. Sexual activity:
1: No sexualactivity
2: At least once a week
3: At least once per 15 days
4: At least once per month
5: Less than once per month

Q19. The psychosocial impact:

- The major groups of psychic repercussions

Anxiety: $\quad 1=$ Yes $\quad 2=\mathrm{No}$

Anxiety: $\quad 1=$ Yes

$2=\mathrm{No}$;

Fear of failure: $\quad 1=$ Yes $\quad 2=\mathrm{No}$;

Mechanical defence reactions

$\begin{array}{llllll}\text { Comprehension: } & 1=\text { Yes } & 2=\mathrm{No} ; & \text { Isolation: } & 1=\mathrm{Yes} & 2=\mathrm{No} \\ \text { Refusal: } & 1=\text { Yes } & 2=\mathrm{No} ; & \text { Dispute: } & 1=\mathrm{Yes} & 2=\mathrm{No} \\ \text { Divorce: } & 1=\text { Yes } & 2=\text { No. } & & \end{array}$

